\title{
Induced Abortion in Colombia: New Estimates And Change Between 1989 and 2008
}

\author{
By Elena Prada, \\ Ann Biddlecom \\ and Susheela \\ singh
}

Elena Prada is an independent consultant based in Bogotá, Colombia. Ann Biddlecom, who was senior research associate at the Guttmacher Institute, New York, when most of the work for this article was completed, is chief, Fertility and Family Planning Section, Population Division, United Nations, New York. Susheela Singh is vice president for research, Guttmacher Institute.

\begin{abstract}
CONTEXT: Although abortion was made legal in Colombia under selected circumstances in 2006, no national studies have examined whether the incidence of the procedure has changed since the previous estimate in 1989.

METHODS: Data on the number of women treated for abortion complications were obtained from a nationally representative survey of 300 public and private health facilities, and estimates of the likelihood that women obtaining abortions experience complications and receive treatment at a facility were obtained from a survey of 102 knowledgeable professionals. Indirect estimation techniques were used to calculate national and regional abortion measures for 2008, which were compared with previously published 1989 estimates. Numbers and rates of unintended pregnancy were also calculated.
\end{abstract}

RESULTS: In 2008, an estimated 93,300 women were treated for induced abortion complications in public and private health facilities. An estimated 400,400 induced abortions were performed, which translates to a rate of 39 per 1,000 women aged 15-44, a slight increase from 1989 (36 per 1,000). Rates varied widely across regions, from 66 in Bogotá to 18 in Oriental. Despite the new abortion law, only 322 legal abortions were performed in 2008. Between 1989 and 2008 , the proportion of pregnancies ending in induced abortion increased from $22 \%$ to $29 \%$, and the proportion of pregnancies that were unintended rose from $52 \%$ to $67 \%$.

CONCLUSION: Improvements in provision of and access to contraceptive and legal abortion services are needed to meet the increased demand among women and couples to prevent unintended pregnancy and unsafe abortion. International Perspectives on Sexual and Reproductive Health, 2011,37(3):114-124

When an abortion is illegal or clandestine, the likelihood that it is unsafe is high. The World Health Organization (WHO) defines unsafe abortion as a procedure to terminate an unintended pregnancy that is performed by an untrained person, carried out in an environment that does not conform to minimum medical standards or both. ${ }^{1}$ The 1994 International Conference on Population and Development in Cairo encouraged governments to treat unsafe abortion as an urgent public health problem. Likewise, in 1999, the United Nations General Assembly cited the prevention of unsafe abortion as one of the strategies that can reduce maternal morbidity and mortality. ${ }^{2}$ In countries with highly restrictive abortion laws, such as most of those in Latin America, many women induce abortions themselves or obtain clandestine, unsafe abortions because they face significant barriers to obtaining safe procedures.

Although abortion laws in Latin America are highly restrictive, an estimated 4.1 million abortions were performed in the region in 2003, a rate of 31 per 1,000 women aged $15-44 .{ }^{3}$ Recent country-specific data are limited, but studies reveal wide variation in abortion rates-33 in Mexico in 2006, ${ }^{4} 24$ in Guatemala in $2003^{5}$ and 54 in Peru in $2000 .{ }^{6}$ Estimates suggest that $95 \%$ of induced abortions in the region are unsafe ${ }^{3}$-about 3.9 million each year. ${ }^{7}$

The few studies that have been published on the magnitude of abortion-related morbidity in Latin America, and on the impact of unsafe abortion on the lives of women in the region, show that the consequences of unsafe procedures are very serious. Unsafe abortion is the fifth most common cause of maternal mortality in $\mathrm{Mexico}^{4}$ and the third most common cause in Guatemala. ${ }^{5}$ Although data for Colombia are scarce, evidence suggests that unsafe abortion was the second most important cause of maternal mortality in the mid-1990s. ${ }^{8}$ Since then, however, unsafe abortion has become a less significant cause: The proportion of maternal deaths resulting from unsafe abortion declined from $16 \%$ in $1994^{8}$ to $9 \%$ in $2007,,^{9}$ and in the past five years unsafe abortion has been the fourth or fifth most common cause of maternal mortality.

Data for Colombia on abortion morbidity-at least regarding cases that reach health facilities-are also scarce. The last national study of the number of women receiving postabortion care is roughly two decades old; it estimated that 58,000 women in Colombia were treated in facilities for complications of unsafe abortion in 1989. ${ }^{10}$

Prior to our study, the most recent data available on abortion incidence in Colombia were from two studies carried out in the early 1990s. One study, using an indirect methodology, estimated that in 1989, about 300,000 induced abortions were performed in Colombia and the national abortion rate was 34 per 1000 women aged $15-49 .{ }^{11}$ The other study, which used a direct methodology, esti- 
mated a rate of 25 per 1,000 urban women aged 15-55 in 1988-1991. ${ }^{12}$ No national studies on the incidence or prevalence of induced abortion have been carried out since then; the estimates that are sometimes cited vary considerably and are not based on actual studies. ${ }^{13}$

Several major changes in the status, methods and availability of abortion in Colombia have occurred since 1989. The most notable of these is legal reform. In a landmark case decided on May 10, 2006, the Constitutional Court of Colombia overturned the strict prohibition on abortion and issued a decision allowing voluntary terminations when the life or health of the woman is in danger, when the fetus has severe malformations and is unlikely to survive outside the womb, and when the pregnancy is the result of rape, incest or nonconsensual insemination or ovular transfer.

Another change is the apparent increase over the past two decades in the use of misoprostol to induce abortion. Misoprostol was first marketed for the prevention and treatment of gastric ulcers under the brand name Cytotec in the late 1980s; ${ }^{14}$ in Colombia, the drug was initially used as an abortifacient (via off-label use) about a decade later. In December 2006, seven months after the partial decriminalization of abortion, the Ministry of Social Protection included misoprostol in its technical guidelines as a permitted method for inducing legal abortion. ${ }^{15}$ Presumably, most current users obtain the drug though the black market, ${ }^{16}$ as sales in the formal sector declined by $87 \%$ from 2002 to 2007. ${ }^{14} \mathrm{Al}$ though no representative national data exist for all women obtaining the drug, $70 \%$ of postabortion patients in a smallscale study fielded in 1999-2002 said they had induced their abortion with misoprostol or another medication, in most cases obtained from pharmacies. ${ }^{17}$ Earlier, a community-based study of urban areas in Colombia found that 19\% of all women who reported having had an induced abortion in the early 1990s said that they had used some type of medication, such as misoprostol. ${ }^{12}$

In addition, women's access to health care (including treatment for abortion complications) has improved in Colombia since 1989, because health care coverage has been expanded, particularly for those who are economically disadvantaged. In 1993, the government approved a reform of the health care system through Law 100, which created a new general social security system of health care. Since then, health insurance coverage among the general population has increased from about 23\% in 1993 (prior to reform) to $88 \%$ in $2008 .{ }^{18}$

Given the changes that have occurred in Colombia since the 1989 national estimates of abortion incidence, the gap in information on this topic is a glaring one. This study provides new national and regional estimates of induced abortion for 2008 and examines how the procedure and the demand for it have changed during the past two decades. In addition, we discuss the implications of our findings for policies and programs designed to reduce the incidence of unsafe abortion and unintended pregnancy and for efforts to provide legal abortion in Colombia.

\section{DATA AND METHODS}

\section{Analytic Approach and Data Sources}

The total number of women having induced abortions includes those who are treated for complications in a health facility, those who are treated for complications but not in a facility (by a trained or untrained provider), those who have complications but receive no care (including those who die) and those who have no complications. We estimated the incidence of induced abortion by first calculating the annual number of women receiving treatment for induced abortion complications in health facilities and then applying a multiplier or inflation factor to account for women who did not have complications, or who had complications but were not treated in a facility.

Our analysis thus draws on two key data sources: a survey of health facilities and a survey of professionals knowledgeable about abortion provision. The first survey provided us with an estimate of the number of women treated for abortion complications in Colombia. The second survey provided us with estimates of the proportions of women obtaining abortions who have complications and seek treatment at a medical facility.

The study design and protocols were adapted from prior research ${ }^{11}$ and revised following review by a project advisory committee in Colombia that consisted of 16 health providers, government officials and researchers familiar with unsafe abortion in the country. The study was also reviewed and approved by the Guttmacher Institute's institutional review board. Questionnaires for both surveys were pretested in February 2009; the final surveys were fielded in March and April 2009 by a staff of eight interviewers and three supervisors.

- Health Facilities Survey. The 2009 Colombian Health Facilities Survey was based on a multistage, stratified cluster sample. The National Territories-which include eight of the country's 32 departments (subdivisions) but only $2 \%$ of the country's population-were excluded from the sample frame because of the difficulty in reaching them and the resulting costs for data collection. First, we stratified the 24 remaining departments and the capital district of Bogotá by region (Atlántica, Bogotá, Central, Oriental and Pacífica). These departments (and the Bogotá district) were further stratified by poverty level (measured as the percentage of the department's total population with unmet basic needs*). Nine departments (and Bogotá) were randomly selected for the survey, with probability of selection proportional to population size.

The second stage was to select a probability sample of health facilities by type and area. From a list of public and private health facilities provided by the Ministry of Social Protection, we identified 1,252 likely to provide abortionrelated services. The proportion of facilities sampled var-

\footnotetext{
*Unmet basic needs is a summary measure based on indicators of housing conditions, economic dependence and the proportion of young children not attending school (source: Departamento Administrativo Nacional de Estadística, Necesidades básicas insatisfechas 1993, no date, $<$ http://www.dane.gov.co/index.php?ltemid=831\&id=346\&option=com content\&sectionid=35\&task=category $>$, accessed Nov. 20, 2008.)
} 
ied depending on the level of specialization in providing postabortion care (classified according to the facility's technological capacity and staff expertise), facility type (primary, secondary or tertiary), type of care provided (inpatient or outpatient) and the number of facilities in a particular sample category (high proportions were sampled for categories that had a small number of facilities, to ensure adequate representation). We sampled 100\% of 138 facilities with the highest level of specialization, including a small number of secondary and primary facilities known to provide postabortion care; $50 \%$ of 194 facilities that either had a medium level of specialization and provided both inpatient and outpatient services, or had a low level of specialization and provided only outpatient care; $10 \%$ of 456 facilities with a medium level of specialization that provided only outpatient care; and 13\% of 464 facilities that had a low level of specialization and provided both outpatient care and inpatient care.

Overall, we selected 339 facilities (or 27\% of the 1,252 in the sampling frame). Thirty-nine of these facilities proved to be ineligible: Eight were listed twice, and 31 were ineligible because they were vacant or closed, had never existed or provided only specialized services unrelated to postabortion care (e.g., cardiology services). Of the 300 remaining facilities, 289 (96\%) participated in the survey and 11 (4\%) did not respond. Survey responses were weighted to take into account the probability of selection and nonresponse. ${ }^{*}$

Surveys were completed by the senior staff member most knowledgeable about the facility's provision of postabortion care, in most cases the director or the staff member in charge of obstetrics and gynecology. Respondents were asked whether their facility provided treatment of spontaneous or induced abortion complications; if so, they were asked to provide the total number of women receiving postabortion care who were treated as outpatients and inpatients in the average month, and the number treated in the past month. Asking about these two time frames increases the likelihood of accurate recall and of capturing monthly variation. The two numbers were averaged and multiplied by 12 to produce an estimate for the calendar year.

The 1989 study used the same methodology as this one, except that in the earlier study, data on abortion complications treated at almost all public health facilities were obtained from hospital records available at the Ministry of Health (now the Ministry of Social Protection), and the number of cases treated in private facilities was

*The weighting factor for a given facility type was the inverse of the subgroup's sampling proportion multiplied by the proportion of completed interviews among sampled facilities.

FFor these facilities, the Health Facilities Survey count of women treated for postabortion complications in 2008 was $20 \%$ higher than the reported ICD-10 figures (30,026 vs. 24,083, unweighted numbers). However, for individual facilities, the ICD-10 counts were sometimes higher than the survey counts. Factors that may have contributed to the differences between the two counts include that the periods covered by the ICD-10 statistics and the Health Facilities Survey estimates were slightly different, and that in some cases ICD-10 statistics were misclassified or incorrectly estimated. Because record-keeping in the health system deteriorated following the 1993 health reforms, complete health statistics are no longer available. However, as a check on the availability of abortion complications data from facilities, we requested such data as part of the Health Facilities Survey for the years 2006-2008, disaggregated by diagnostic codes from the 10th revision of the International Classification of Diseases (ICD-10). Fewer than half $(46 \%)$ of the sampled facilities that offered postabortion care were able to provide information for 2008 using ICD-10 codes, and this subset of facilities accounted for only $43 \%$ of postabortion cases estimated from the Health Facilities Survey. ${ }^{\dagger}$ Thus, data maintained by facilities are currently too incomplete to be the basis of national estimates of abortion incidence. However, for the facilities that had such data, the counts were quite close to the Health Facilities Survey counts of postabortion complications.

- Health Professionals Survey. A separate survey was conducted among knowledgeable professionals to obtain opinions about the context of abortion provision and postabortion care. A purposive sample of key expertsboth medical and nonmedical-was selected on the basis of their affiliation, experience and expertise on the topic. Their responses were used to calculate the multiplier or adjustment factor that accounts for the proportion of women having induced abortions who do not experience complications or who do not obtain medical treatment in a formal health facility.

The survey questionnaire was similar to the one used in the earlier study, with two important modifications: We added questions on use of misoprostol (a topic not examined in the earlier study, because this drug was rarely used to induce abortion in Colombia in the late 1980s and early 1990s) and the 2006 court ruling on abortion. A total of 102 knowledgeable professionals were selected and interviewed. Respondents were based in four of the country's five major regions. ${ }^{\ddagger}$ Although almost all professionals interviewed worked in urban areas, we ensured that we had sufficient representation of experts with experience working in rural areas.

Data on contraceptive use, planning status of births and unmet need for contraception were obtained from Demographic and Health Surveys (DHS) carried out in Colombia in $1990,{ }^{19} 2000,{ }^{20} 2005^{21}$ and $2010 .{ }^{22}$ These largescale surveys had nationally representative samples of women aged 15-49 ranging in size from 8,644 in 1990 to 49,818 in 2010 . $\$$

coded. Because our estimation technique relies on several assumptions, our methodology produces a range of estimates around a midpoint estimate (i.e., based on the medium multiplier); the difference between the ICD-10 statistics and the Health Facilities Survey estimates may fall within this range.

¥The Oriental region was not included in the Health Professionals Survey because of the difficulty of finding 25 respondents knowledgeable about abortion services in this region; budget constraints also contributed to this decision.

$\S$ All data presented in this article from the four DHS surveys exclude the National Territories, which were not included in our study. 


\section{Estimating the Incidence of Induced Abortion}

- Women treated for abortion complications. Data from the Health Facilities Survey were used to quantify the number of women treated for complications of spontaneous and induced abortion in 2008. From this number we needed to exclude women with complications from spontaneous abortion. Determining whether complications are due to attempted induced abortion or to a spontaneous abortion is difficult, because the symptoms of the two are very similarin both cases, heavy bleeding is the main symptom. In addition, respondents may be unwilling to report that complications at their facilities are the result of induced abortion because of the legal restrictions on the procedure.

To address this challenge, we used data from clinical studies on the prevalence of spontaneous pregnancy $\operatorname{loss}^{23}$ to estimate the proportion of pregnant women who experience late spontaneous pregnancy loss (13-21 weeks' gestation) and are thus likely to require care at a health facility.* The number of pregnancies that end in spontaneous pregnancy loss at 13-21 weeks is roughly equivalent to $3.4 \%$ of all live births; ${ }^{\dagger 24}$ in 2008 , there were an estimated 764,300 live births in Colombia. ${ }^{\dagger}$

The standard indirect estimation methodology requires a further adjustment, because not all women needing treatment for complications of late spontaneous abortion obtain care in a facility. We assumed that this proportion is similar to the proportion of births that occur in a health facility. Nationally, 95\% of women deliver in a health facility; regionally, the proportion ranges from $91 \%$ in Pacífica to $100 \%$ in Bogotá. ${ }^{25}$ After we adjusted the data accordingly, an estimated 19\% of postabortion treatment cases were for complications of late miscarriage and $81 \%$ were for complications of induced abortion in 2008.

However, assessment of the regional data indicated that an adjustment was needed for the Oriental region: The proportion of postabortion patients estimated to have had spontaneous abortions (55\%) $)^{\S}$ far exceeded the proportions for the other four regions (16\%-36\%, and $22 \%$ for the four regions combined). Further examination revealed that the sample of facilities in the Oriental region that were randomly selected for the Health Facilities Survey did not include any of the large facilities that provide the bulk of postabortion care in the region. This also helps explain the exceptionally low rate of postabortion treatment for this region (four cases per 1,000 women aged 15-44). To ad-

*Although the likelihood of spontaneous pregnancy loss is much higher before the 13th week of gestation than it is during weeks $13-21$, the frequency and severity of complications are much lower; thus, women are less likely to need medical treatment before week 13. Spontaneous pregnancy losses after 21 weeks are not included because they are classified as fetal deaths rather than spontaneous abortions.

†About $2.89 \%$ of pregnancies recognized at six weeks' gestation end in spontaneous abortion during weeks $13-21$; because $84.575 \%$ of recognized pregnancies result in live births, the number of spontaneous abortions during weeks $13-21$ is roughly equal to $3.417 \%$ of the number of live births (2.89/84.575).

$\neq$ We calculated this number by applying age-specific fertility rates from the 2010 DHS to the number of women in relevant age-groups in 2008, dress this data quality issue, we assumed that the proportion of postabortion cases in the Oriental region that were the result of spontaneous abortion was the average of the proportions for the other four regions (22\%).

- Multipliers. As mentioned earlier, not all women who have induced abortions experience complications or obtain medical treatment in a health facility. To account for these cases, a multiplier must be developed and applied to the number of abortion complication cases treated in facilities to estimate the total number of women who had an induced abortion. As a rule of thumb, the safer a region's abortion services are, the higher the multiplier will be, because a lower proportion of women will require medical treatment for complications. The multiplier is also affected by women's access to health facilities. If facilities are easily reached, the proportion of women with complications who receive treatment will be higher; in poor or underserved areas, by contrast, fewer women with serious complications will be able to get treatment.

We obtained the data needed to estimate the multiplier from the Health Professionals Survey. Respondents were asked to make several estimates: the percentage distribution of women who obtain induced abortions according to type of abortion provider; the proportions of women who are likely to experience complications requiring medical care, again according to provider type; and the probability that women who have complications will receive medical care from a facility. Categories of providers included doctors (both obstetricians/gynecologists and general practitioners); trained nurses and midwives; pharmacists; untrained practitioners (principally traditional birth attendants); and women themselves. An additional category for misoprostol (regardless of who provided it) was also included. All categories were mutually exclusive.

Respondents provided this information for each of four key subgroups of women-urban poor, urban nonpoor, rural poor and rural nonpoor-because the conditions under which women obtain abortions vary by their ability to pay and their access to providers. ${ }^{*} 26$

From these data we estimated, for each of the four subgroups, the proportion of women having an induced abortion who are treated at facilities for abortion complications. These percentages were weighted by the relative size of the subgroups nationally and regionally to yield multipliers for the country and for each region. On the basis of these calculations, we established a range of abortion estimates both nationally and for each of the five major regions. Estimates of the number of women of reproductive age were interpolated from 2005 census data and official government estimates for 2010 .

$\S$ An estimated 8,563 patients were treated in health facilities for abortion complications in Oriental, according to the Health Facilities Survey. Using the indirect technique, we estimated that the number of these patients who had had spontaneous abortions equaled the product of 139,081 (the annual number of births in this region) multiplied by $3.41 \%$, or 4,743 women-approximately $55 \%$ of all postabortion patients in this region.

**Poor and nonpoor were defined using women's level of education, as data on income are not reliable for Colombia.Poor women were defined as those who had had seven or fewer years of schooling, and nonpoor women as those with eight or more years of schooling (source: reference 22). 
TABLE 1. Measures used to calculate the number of women having induced abortions, by region, Colombia, 2008

\begin{tabular}{|c|c|c|c|c|c|c|c|c|c|}
\hline \multirow[t]{2}{*}{ Region } & \multirow{2}{*}{$\begin{array}{l}\text { No. of } \\
\text { women } \\
\text { aged 15-44 }\end{array}$} & \multirow{2}{*}{$\begin{array}{l}\text { No. of live } \\
\text { births }\end{array}$} & \multicolumn{3}{|c|}{ No. of women treated } & \multirow{2}{*}{$\begin{array}{l}\text { Rate of } \\
\text { treatment } \\
\text { for induced } \\
\text { abortion } \neq\end{array}$} & \multicolumn{3}{|c|}{ Multipliers§ } \\
\hline & & & $\begin{array}{l}\text { Spontaneous } \\
\text { or induced } \\
\text { abortion }\end{array}$ & $\begin{array}{l}\text { Spontaneous } \\
\text { abortion* }\end{array}$ & $\begin{array}{l}\text { Induced } \\
\text { abortiont }\end{array}$ & & Low & Medium & High \\
\hline All & $10,222,960$ & 764,338 & 115,325 & 21,989 & 93,336 & 9.1 & 3.29 & 4.29 & 5.29 \\
\hline Atlántica & $2,190,126$ & 205,174 & 27,506 & 6,668 & 20,838 & 9.5 & 3.40 & 4.44 & 5.47 \\
\hline Bogotá & $1,789,946$ & 120,690 & 28,023 & 4,095 & 23,928 & 13.4 & 3.77 & 4.92 & 6.07 \\
\hline Central & $2,615,946$ & 173,640 & 19,223 & 5,690 & 13,533 & 5.2 & 3.54 & 4.62 & 5.70 \\
\hline Oriental & $1,822,051$ & 139,081 & 8,563 & 1,655 & 6,908 & 3.8 & 3.54 & 4.62 & 5.70 \\
\hline Pacífica & $1,804,891$ & 125,753 & 32,010 & 3,881 & 28,129 & 15.6 & 2.64 & 3.44 & 4.24 \\
\hline
\end{tabular}

*Calculation assumes that the proportion of women with spontaneous abortions who obtain treatment in a health facility is the same as the proportion of women giving birth who deliver in hospitals. tEquals the number of women treated for any abortion complication minus the number treated for spontaneous abortion. ₹Rate is number of treated cases per 1,000 women aged 15-44. \$Medium multipliers were derived from the Health Professionals Survey. For the national values, the low and high multipliers were set at one unit below and one unit above the medium multiplier, respectively. For individual regions, the low and high multipliers were calculated by keeping the ratios between the low, medium and high multipliers the same as the ratios at the national level.

(low, medium and high) for the country and for each region (Table 1). The medium national multiplier was 4.3, and the low and high variants were estimated as one unit (approximately 25\%) above and below this average (3.3 and 5.3, respectively). At the regional level, the medium multipliers ranged from 3.4 (Pacífica) to 4.9 (Bogotá); the low and high variants for each region were calculated to reflect the same ratios between variants as the national-level multipliers.

\section{Estimating Unintended and Intended Pregnancies}

The sum of all live births, abortions and miscarriages (from intended and unintended pregnancies) yields the total number of pregnancies. To calculate the number of unintended pregnancies, nationally and by region, we first added the number of abortions (determined using the approach described above) to the number of unplanned births (derived by multiplying the proportion of recent births that had been unplanned ${ }^{*}$-obtained from the 2010 DHS ${ }^{25}$-by the number of live births in 2008). To this sum we added the number of unintended pregnancies ending in miscarriage, which we estimated using a model-based approach derived from clinical studies of pregnancy loss by gestational age. ${ }^{23,24}$ According to this model, the number of unintended pregnancies ending in miscarriage is approximately equal to $20 \%$ of the number of live births resulting from unintended pregnancies plus $10 \%$ of the number of induced abortions. Applying this approach to the number of unplanned births in 2008 yielded an esti-

\begin{tabular}{|c|c|c|c|c|c|c|c|c|c|}
\hline \multirow[t]{2}{*}{ Region } & \multicolumn{3}{|c|}{ No. of induced abortions } & \multicolumn{3}{|c|}{ Abortion rate* } & \multicolumn{3}{|c|}{ Abortion ratiot } \\
\hline & Low & Medium & High & Low & Medium & High & Low & Medium & High \\
\hline All & 307,706 & 400,412 & 493,748 & 30.1 & 39.2 & 48.3 & 40.3 & 52.4 & 64.6 \\
\hline Atlántica & 70,711 & 92,284 & 113,696 & 32.3 & 42.1 & 51.9 & 34.5 & 45.0 & 55.4 \\
\hline Bogotá & 90,032 & 117,422 & 144,874 & 50.3 & 65.6 & 80.9 & 74.6 & 97.3 & 120.0 \\
\hline Central & 47,812 & 62,360 & 76,941 & 18.3 & 23.8 & 29.4 & 27.5 & 35.9 & 44.3 \\
\hline Oriental & 24,405 & 31,831 & 39,273 & 13.4 & 17.5 & 21.6 & 17.5 & 22.9 & 28.2 \\
\hline Pacífica & 74,116 & 96,515 & 118,964 & 41.1 & 53.5 & 65.9 & 58.9 & 76.7 & 94.6 \\
\hline
\end{tabular}

*Number of abortions per 1,000 women aged 15-44. †Number of abortions per 100 live births. mate of the number of unintended pregnancies ending in miscarriage that year and allowed us to determine the number of unplanned pregnancies.

The number of intended pregnancies was calculated in a similar fashion-by applying the proportion of births that were planned to the number of live births, and then adding the number of intended pregnancies ending in miscarriage. Abortions were not included in this calculation, because we assumed that pregnancies ending in abortion are unintended.

\section{RESULTS \\ Abortion Morbidity}

From responses to the Health Facilities Survey, we estimate that 115,300 women were treated in health facilities in 2008 for complications resulting from induced or spontaneous abortion (Table 1); the public and private sectors shared about equally in providing postabortion care (not shown). The majority of patients-93,300-were treated for complications of induced abortion, and the remaining 22,000 received treatment for late miscarriage (Table 1).

Information from the Health Professionals Survey indicates that $33 \%$ of all women who obtain abortions experience complications that need medical treatment; $79 \%$ of these women receive facility-based care, but the remaining 21\% do not (not shown). The national annual rate of treatment of induced abortion complications was nine per 1,000 women aged 15-44. Women living in the Pacífica and Bogotá regions had higher than average estimated treatment rates: 16 and 13 , respectively. The high rate in Bogotá is most likely related to women in this region having high levels of access to health services, as well as to the high abortion rate in Bogotá. Because three of Pacífica's four departments are among the poorest in the country, the high treatment rate in this region is more likely the result of use of unsafe methods than of use of health services. Though socioeconomic indicators for the Central region are generally similar to those of Pacífica, 
the treatment rate for postabortion complications in the Central region is far lower-just five per 1,000 women aged 15-44. The Oriental region has the lowest treatment rate (four); this rate is likely an underestimate.

At $93 \%$ of the facilities sampled in the Health Facilities Survey, dilation and curettage (D\&C) was the most commonly used method in postabortion care; manual vacuum aspiration was the most commonly used method at only $7 \%$ of facilities (not shown).

\section{Abortion Incidence}

Our medium estimate of the number of induced abortions in Colombia in 2008 was 400,400; the low estimate was 307,700 and the high estimate was 493,700 (Table 2). The medium estimate of the abortion rate was 39 per 1,000 women of reproductive age, while the low and high estimates were 30 and 48, respectively. As with abortion morbidity, regional variation in abortion rates was substantial. The medium estimate of the abortion rate was highest in Bogotá (66 per 1,000 women aged 15-44) and lowest in Oriental (18 abortions per 1,000). Estimates for the other regions fall within this range: 24 in Central, 42 in Atlántica and 54 in Pacífica.

The medium estimate of the national abortion ratio was 52 abortions per 100 live births; the low and high estimates were 40 and 65 , respectively. The medium ratio in Bogotá (97 per 100 live births) was almost twice the national estimate, while that in the Oriental region (23) was less than half the national ratio.

The Health Facilities Survey asked respondents how many legal abortions their facility had provided in 2008. By weighting their responses, we calculate that 322 legal abortions were performed in Colombia in 2008 (not shown).

\section{Trends in Abortion Morbidity and Incidence}

The number of women treated for complications of induced abortion in Colombia increased from 57,700 in 1989 to 93,300 in 2008 (Table 3). This is an increase of $62 \%$, more than twice the increase in the population of women aged 15-44 (28\%). The estimated rate of treatment for complications of induced abortion increased by $26 \%$, from seven cases per 1,000 women of reproductive age to nine cases. Health system reforms and the increase in the use of misoprostol probably played a role in this increase.

The number of induced abortions in Colombia increased from 288,400 in 1989 to 400,400 in 2008, an increase of $39 \%$. However, the abortion rate increased by only $8 \%$, from 36 to 39 per 1,000, mainly because the population of women of reproductive age increased at a rate (28\%) not very different from that of the number of abortions. The abortion ratio increased sharply, by $49 \%$, from 35 induced abortions per 100 live births in 1989 to 52 per 100 live births in 2008; this rise was due mostly to the decline in fertility in Colombia. In sum, while the rate of abortion complications and the ratio of induced abortions to
TABLE 3. Selected demographic and abortion-related measures, by year, and percentage change between 1989 and 2008, Colombia

\begin{tabular}{|c|c|c|c|}
\hline Measure & $1989^{*}$ & 2008 & $\begin{array}{l}\% \\
\text { change }\end{array}$ \\
\hline \multicolumn{4}{|l|}{ Demographic } \\
\hline No. of women aged $15-44$ & $7,968,123$ & $10,222,960$ & 28 \\
\hline No. of births & 820,017 & 764,338 & -7 \\
\hline \multicolumn{4}{|c|}{ No. of women treated for abortion complications } \\
\hline Any abortion & 76,905 & 115,325 & 50 \\
\hline Spontaneous abortion & 19,226 & 21,989 & 14 \\
\hline Induced abortion & 57,679 & 93,336 & 62 \\
\hline \multicolumn{4}{|l|}{ Abortion measures } \\
\hline No. of induced abortions & 288,395 & 400,412 & 39 \\
\hline Abortion rate† & $36.2 \neq$ & 39.2 & 8 \\
\hline Abortion ratio§ & 35.2 & 52.4 & 49 \\
\hline \multicolumn{4}{|l|}{ Induced abortion } \\
\hline treatment rate ${ }^{* *}$ & 7.2 & 9.1 & 26 \\
\hline
\end{tabular}

*Unless otherwise noted, data for 1989 are from reference 11. †Number of abortions per 1,000 women aged 15-44. $\neq$ The originally published rate (33.7) was per 1,000 women aged 15-49; we recalculated the rate per 1,000 women aged 15-44. §Number of abortions per 100 live births. ${ }^{* *}$ Cases per 1,000 women aged 15-44.

FIGURE 1. Percentage distribution of pregnancies, by outcome, Colombia, 1989 and 2008

1989

$1,301,240$ pregnancies

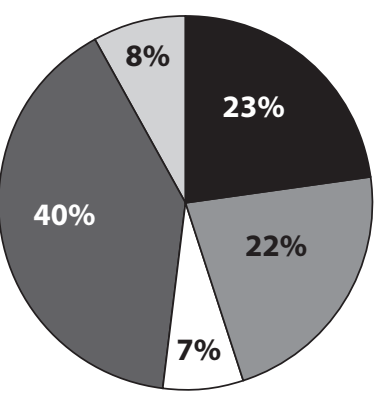

2008

$1,357,659$ pregnancies

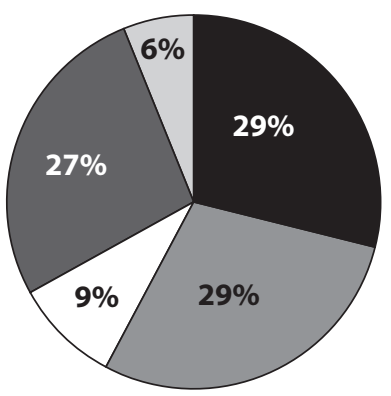

Unplanned births

Induced abortions

Unintended pregnancies ending in miscarriage

Planned births

Intended pregnancies ending in miscarriage 


\begin{tabular}{|c|c|c|c|c|c|c|c|c|c|c|c|c|}
\hline \multirow[t]{3}{*}{ Region } & \multicolumn{8}{|c|}{$\%$ using a method } & \multicolumn{4}{|c|}{$\%$ with unmet need $\neq$} \\
\hline & \multicolumn{4}{|c|}{ Modern* } & \multicolumn{4}{|c|}{ Traditional† } & & & & \\
\hline & 1990 & 2000 & 2005 & 2010 & 1990 & 2000 & 2005 & 2010 & 1990 & 2000 & 2005 & 2010 \\
\hline All & 54.6 & 63.3 & 67.5 & 72.8 & 11.5 & 13.6 & 10.7 & 6.3 & 11.1 & 6.2 & 5.8 & 6.9 \\
\hline Atlántica & 48.4 & 57.3 & 59.0 & 65.0 & 5.0 & 13.5 & 11.4 & 6.5 & 18.3 & 9.0 & 9.6 & 10.2 \\
\hline Bogotá & 61.8 & 68.7 & 74.1 & 75.7 & 13.0 & 11.9 & 8.4 & 5.1 & 7.9 & 4.5 & 3.6 & 5.4 \\
\hline Central & 53.1 & 62.8 & 69.4 & 75.3 & 12.4 & 13.9 & 10.4 & 6.4 & 9.6 & 5.5 & 4.9 & 5.4 \\
\hline Oriental & 57.0 & 66.4 & 69.6 & 75.2 & 16.7 & 16.1 & 11.8 & 6.3 & 7.5 & 3.7 & 4.4 & 6.0 \\
\hline Pacífica & 54.8 & 64.2 & 66.9 & 73.5 & 10.9 & 12.1 & 11.3 & 6.9 & 11.8 & 7.6 & 5.5 & 7.7 \\
\hline
\end{tabular}

*Includes condom, implant, injectable, IUD, pill, spermicide and female or male sterilization. IIncludes periodic abstinence, withdrawal, lactational amenorrhea and folk methods. 㚿centage who are fecund, do not want a child in the next two years (or ever) and are not using any method of contraception. Sources: Special tabulations of data from Demographic and Health Surveys (references 19-22).

births increased markedly in Colombia during the past two decades, the abortion rate changed relatively little.

\section{Abortion in Context}

The incidence of abortion, and any changes in this measure over time, must be understood in the context of unintended pregnancy, fertility, contraceptive use and unmet need for contraceptive methods. The proportion of pregnancies that resulted in induced abortion increased from 22\% in 1989 to 29\% in 2008 (Figure 1, page 119). A similar rise occurred in the proportion of pregnancies resulting in unplanned births (from 23\% to 29\%), while a concomitant decrease occurred in the proportion ending in planned births (from $40 \%$ to $27 \%$ ). Thus, the proportion of pregnancies that were unintended-i.e., those ending in abortion, mistimed birth or unwanted birth, and unintended pregnancies ending in miscarriage-rose by $29 \%$ in Colombia during the past two decades, from $52 \%$ to $67 \%$. The overall pregnancy rate fell from 163 to 133 per 1,000 women aged 15-44, while the unintended pregnancy rate rose from 84 to 89 (not shown). The trend in unintended pregnancy was largely determined by trends in the planning status of births; according to DHS data, the proportion of recent births that were unplanned (mistimed or not wanted at all) increased from 36\% in 1990 to $51 \%$ in $2010 .^{19,22}$

The prevalence of use of modern contraceptives (the pill, IUD, injectable, implant, spermicides, male condom and female and male sterilization) was already relatively high in 1990 among women in union (55\%), and it increased to $73 \%$ by 2010 (Table 4). The proportion of women in union using traditional methods, which have high failure rates, declined from $12 \%$ to $6 \%$, but this is still a substantial group at high risk of unintended pregnancy. Moreover, method discontinuation is very common: An analysis of 2005 DHS data found that 44\% of married women using contraceptive methods other than female sterilization discontinued use within 12 months. ${ }^{27}$ The proportion of women in union with an unmet need for contraception* declined from $11 \%$ in 1990 to $6 \%$ in 2000, but it basically remained at this level in 2005 and 2010 (Table 4). Similarly, the proportion of women using any type of contraceptive (modern or traditional) did not change meaningfully between 2000 (77\%) and 2010 (79\%).

Among young women aged 15-24 who were not in a union, the proportion who were sexually active increased steeply between 1990 and 2010, from 8\% to 31\% (not shown). Although the proportion of sexually active women in this age-group who were using modern contraceptive methods more than doubled during this time period (from 25\% to 64\%), the proportion with unmet need (and thus at risk for unintended pregnancy) increased from 5\% in 2000 to $8 \%$ in 2010 (data are unavailable for 1990). Moreover, in 2010, about 5\% of these young women were using traditional methods and thus were at risk for unintended pregnancy (not shown).

\section{DISCUSSION}

Data on the incidence of induced abortion and its complications are limited for much of the world, including Colombia; almost two decades have passed since the last estimate of abortion incidence. The current study, which provides new data, is timely given the significant changes that have occurred in Colombia during the past 20 yearslegal and health system reforms, fertility decline, increased contraceptive use and the rise of medication abortion-and the effects these changes may have had on the incidence and safety of abortion.

Significant gaps and needs remain regarding postabortion care. An estimated 21\% of the women who needed treatment for postabortion complications did not receive such care. In addition, more than $90 \%$ of facilities sampled in the Health Facilities Survey reported that D\&C was their most commonly used method in postabortion care, even though manual vacuum aspiration is the WHOrecommended standard of care. ${ }^{2}$ Moreover, not all facilities that provide postabortion care comply with the recommendation to include contraceptive counseling as part of such care to help women prevent unintended pregnancies and thus reduce the need for future abortions. ${ }^{2}$ Among facilities in the Health Facilities Survey that reported providing postabortion care, $11 \%$ did not provide family planning counseling and 30\% did not provide contraceptives.

Between 1989 and 2008, the estimated rate of facilitybased treatment of postabortion patients increased from seven to nine cases per 1,000 women aged 15-44. This increase is likely the result of two factors: increased use of misoprostol and improved access to postabortion care. Misoprostol can be very effective (85-90\%) in inducing abortions during the first nine weeks of pregnancy, and because it leads to few complications when administered correctly, ${ }^{28}$ it can reduce the risk of complications if it replaces methods that are much less safe. However, widespread use may increase complication and treatment rates if providers

*Women are considered to have an unmet need for contraception if they are fecund and married, are not using any method of contraception, and do not want a child in the next two years or ever. 
commonly use the drug incorrectly, or if large numbers of women take it themselves and use it either incorrectly or beyond nine weeks' gestation (the limit for maximal effectiveness). In addition, it is possible that some women who have used misoprostol correctly may prefer (or be advised) to go to a health facility to have the abortion completed once bleeding begins, even though the abortion may be safely completed without medical care, thus further increasing the treatment rate.

The potential impact of these issues is illustrated by evidence from Mexico and other Latin American countries, where the rate of incomplete abortion resulting from misoprostol use is often substantially higher than the rates achieved in clinical studies. ${ }^{29,30}$ In Colombia, since the early 1990s, misoprostol use has replaced safe, physicianprovided surgical procedures as well as highly unsafe abortions performed by untrained providers, and these two trends have cancelled each other out to a large extent. ${ }^{31}$ Nonetheless, misoprostol, if used properly, can reduce the severity of complications from unsafe induced abortions. In the late 1970 s, $95 \%$ of postabortion patients in Colombia were hospitalized, and only $5 \%$ were treated as outpatients, ${ }^{32}$ while in 2008 just $20 \%$ of postabortion cases were treated as inpatients and $80 \%$ as outpatients.

Another factor that may account for the rise in the rate of treatment for induced abortion complications is women's increased access to health care. Following reform of Colombia's health care system in 1993, health insurance coverage more than tripled, increasing from $23 \%$ of the population in 1993 to $88 \%$ in $2008 .{ }^{18}$ However, in spite of this great expansion in coverage, inequities still exist; rural and poor people still have much lower coverage than the urban and nonpoor population. In addition, it is important to note that having health insurance does not guarantee access to or availability of services.

Our findings show that the rate of induced abortion has changed relatively little during the past two decades. Colombia's abortion rate (39 per 1,000 women aged 15-44) is still much higher than the average rate for the developing world (29). ${ }^{26}$ However, the number of facilitybased legal abortions in this study was very small (322 cases in 2008), perhaps in part because not much time had elapsed between the May 2006 ruling on abortion (guidelines on the implementation of which were not published until December 2006) and our data collection.

Although the overall pregnancy rate declined between 1989 and 2008, the proportion of pregnancies that were unintended increased by $29 \%$, and the unintended pregnancy rate increased by $7 \%$. The increase in the latter stands in contrast to worldwide trends: The unintended pregnancy rate in the developing world declined by $20 \%$ between 1995 and 2008. ${ }^{26}$ The findings on unintended pregnancy and abortion in Colombia must be viewed in light of trends in women's fertility goals and gaps in contraceptive use. Although contraceptive use increased between 1990 and 2000 and the proportion of women using traditional methods declined between 2005 and 2010, other data suggest that progress in this area has stalled. Contraceptive prevalence did not increase and unmet need did not decline between 2000 and 2010, even though the trend of women wanting smaller families continued. ${ }^{20,22}$ In addition, the relatively low level of unmet need suggests that persistent high levels of unintended pregnancy may be related to inconsistent or ineffective use of modern methods. Focused counseling and better followup services can help to improve the quality of contraceptive use by reducing discontinuation and incorrect use.

The large increase in Colombia during the past two decades in the number of displaced persons-a population inadequately served by health services, including contraceptive services-may also affect trends in unintended pregnancy, ${ }^{33}$ as may the substantial proportion of unmarried young women who are sexually active and not using contraceptives. These factors, combined with increased demand for effective pregnancy prevention, help explain the increase in unintended pregnancy and lack of a decline in induced abortion.

\section{Limitations}

Our data and analytical approach have some limitations. Because of the lack of official statistics on abortion complications treated at health facilities, we relied on estimates by health staff at the sampled facilities. To assist respondents with recalling or estimating complication caseloads, we asked them about the number of women treated for complications in the past month and the number treated in an average month. This design takes into account the likelihood that caseloads fluctuate across months, and that consequently the past month may not have been typical. Furthermore, asking respondents to present the information in two ways provides an internal cross-check.

Another limitation is that our approach makes assumptions about the rate of late spontaneous abortion, the probability of complications from induced abortion and the likelihood that women receive health care for complications they experience. The estimated rate of late-and indeed all-spontaneous abortions was based on clinical studies conducted in the 1980s. Although biological patterns of spontaneous abortion are fairly stable, they may have changed in the intervening decades because of changes in lifestyles, nutrition and the environment.

Moreover, given the paucity of data on abortion complication rates and health-seeking behavior in the general population, we relied on the opinions of professionals to estimate the probability that women experience abortionrelated complications and that those who do seek care. To obtain the best estimates, we selected and interviewed the most knowledgeable professionals in this field.

A limitation of our analysis of trends in induced abortion is that data on complications treated at facilities were from two sources. The 1989 data were obtained from official hospital discharge statistics, while the 2008 data were calculated from responses to a survey of knowledgeable health facility staff (because complete, accurate health facility 
records were not available). Finally, we were unable to examine regional trends in induced abortion, because the 1989 Health Professionals Survey was not large enough to permit calculation of region-specific multipliers.

\section{Implications for Policies and Programs}

This study has several implications for abortion-related and contraceptive services in Colombia. The increase in the unintended pregnancy rate and the continued high incidence of abortion during the past two decades, combined with evidence that the country's family planning program effort has lost momentum in the past decade, strongly suggest that family planning services need to be improved. This service gap is underscored by the unfulfilled needs of special groups, such as the displaced population and unmarried young women. Our findings highlight the urgent need to give higher priority and allocate greater resources to improving the coverage and quality of family planning information and services for all groups and all areas of the country.

Two years after the 2006 court ruling that allowed abortion under three limited circumstances, the number of legal procedures performed was extremely small-322 cases in 2008. The Ministry of Social Protection is making efforts to expand access to legal abortion services, but in 2009 only about one in nine (11\%) health facilities in our sample offered legal abortions. Increased efforts by the government, and by all concerned stakeholders, are needed to ensure that the 2006 ruling is fully implemented and that women who meet the criteria have access to legal abortion services.

Because of the lack of empirical data on abortion, little detailed evidence is available on the characteristics of women who obtain abortions and the reasons they do so. However, the Health Professionals Survey highlights some basic differences among subgroups in women's access to safe abortion. For example, respondents estimated that $25 \%$ of abortions obtained by nonpoor urban women were induced by a physician using a method other than misoprostol, compared with just $4 \%$ of the abortions obtained by poor rural women. ${ }^{34}$ In contrast, $32 \%$ of the abortions obtained by poor rural women were induced by a traditional midwife using a method other than misoprostol, compared with only $2-15 \%$ of those obtained by women in the other three subgroups. More research is needed to identify the groups of women who are most likely to obtain unsafe abortions, most at risk for complications from such procedures and most in need of effective pregnancy prevention.

Results of this study also point to the need for improvements in postabortion care. Coverage needs to be expanded to reach the women with postabortion complications who do not receive medical care. In addition, the use of manual vacuum aspiration or misoprostol (an effective method of postabortion care) to treat complications of first-trimester abortion needs to be increased, as recommended by WHO, while use of the less cost-effective and less appropriate D\&C technique should be reduced. More providers should be trained to perform manual vacuum aspiration, and supplies of manual vacuum aspiration kits need to be increased, as the numbers distributed in 2008 and 2009 were small (169 and 192, respectively). ${ }^{35}$ Finally, expanded provision of contraceptive counseling and services is needed to reach all postabortion patients to improve their contraceptive use and avoid repeat abortion.

The results of the present study should raise awareness among policymakers and program managers of the difficulty that Colombian women and couples are still having in preventing unintended pregnancy and unplanned births. The study also provides evidence that unsafe abortion remains prevalent in all parts of the country, continues to have a substantial impact on women's health and consumes scarce health care resources. Yet, the impact of unsafe abortion can be reduced through appropriate contraceptive and abortion-related policies and programs, and by increasing access to legal abortion services.

\section{REFERENCES}

1. World Health Organization (WHO), The Prevention and Management of Unsafe Abortion: Report of a Technical Working Group, Geneva: WHO, 1992

2. WHO, Safe Abortion: Technical and Policy Guidance for Health Systems, Geneva:WHO, 2003.

3. Sedgh G et al., Induced abortion: estimated rates and trends worldwide, Lancet, 2007, 370(9595):1338-1345.

4. Juarez F et al., Estimates of induced abortion in Mexico: What's changed between 1990 and 2006? International Family Planning Perspectives, 2008, 34(4):158-168

5. Singh S, Prada E and Kestler E, Induced abortion and unintended pregnancy in Guatemala, International Family Planning Perspectives, 2006, 32(3): 136-145

6. Ferrando D, El Aborto Clandestino en el Perú: Hechos y Cifras, Lima, Peru: Flora Tristán and Pathfinder International, 2002

7. WHO, Unsafe Abortion: Global and Regional Estimates of the Incidence of Unsafe Abortion and Associated Mortality in 2003, fifth ed., Geneva: WHO, 2007.

8. Ministerio de Salud et al., Mortalidad Materna en Colombia, Bogotá, Colombia: Ministerio de Salud, 1996.

9. Departamento Administrativo Nacional de Estadística Colombia, Defunciones 2007: Cuadro 7, defunciones maternas, por grupos de edad, según departamento de residencia, año 2007, <http:// www.dane.gov.co/index.php?option=com_content\&task=category \&sectionid=16\&id=535\&Itemid=1035>, accessed Feb. 22, 2011.

10. The Alan Guttmacher Institute (AGI), Aborto Clandestino: Una Realidad Latinoamericana, New York: AGI, 1994.

11. Singh S and Wulf D, Estimated levels of induced abortion in six Latin American countries, International Family Planning Perspectives, 1994, 20(1):4-13

12. Zamudio L, Rubiano $\mathrm{N}$ and Wartenberg L, El Aborto Inducido en Colombia: Características Demográficas y Socioculturales, Bogotá, Colombia: Centro de Investigaciones Sobre Dinámica Social, Universidad Externado de Colombia, 1999.

13. Moloney A, Unsafe abortions common in Colombia despite law change, Lancet, 2009, 373(9663):534.

14. Fernández $\mathrm{M}$ et al., Assessing the global availability of misoprostol, International Journal of Gynecology and Obstetrics, 2009, 105(2):180-186.

15. Ministerio de la Protección Social, Documentación Complementaria y Norma Técnica para la Atención de la Interrupción Voluntaria del Embarazo, Bogotá, Colombia: Ministerio de la Protección Social, 2006. 
16. Gynuity, Opciones para la Introducción del Aborto con Medicamentos en Brasil, Colombia, México y Perú, New York: Gynuity, 2007.

17. Gómez-Sánchez PI, Escandón I and Gaitán-Duarte H, Evaluación de la atención integral al pos-aborto en 13 hospitales de Colombia, Revista de Salud Pública, 2007, 9(2):241-252.

18. Ministerio de la Protección Social and WHO, Situación de Salud en Colombia: Indicadores Básicos, 2008, Bogotá, Colombia: Instituto Nacional de Salud, 2008.

19. Profamilia, Encuesta de Prevalencia, Demografía y Salud, Colombia, 1990, Bogotá, Colombia: Profamilia; and Columbia, MD, USA: Institute for Research Development/Macro International, 1991.

20. Profamilia, Salud Sexual y Reproductiva: Resultados Encuesta Nacional de Demografía y Salud, 2000, Bogotá, Colombia: Profamilia, 2000.

21. Profamilia, Salud Sexual y Reproductiva en Colombia: Resultados Encuesta Nacional de Demografía y Salud, 2005, Bogotá, Colombia: Profamilia; and Calverton, MD, USA: ORC Macro, 2005.

22. Profamilia, Encuesta Nacional de Demografía y Salud, Colombia, 2010, Bogotá, Colombia: Profamilia, 2011.

23. Bongaarts J and Potter R, Fertility, Biology and Behavior, New York: Academic Press, 1983.

24. Harlap S, Shiono PH and Ramacharan S, A life table of spontaneous abortions and the effects of age, parity, and other variables, in: Porter IH and Hook EB, eds., Human Embryonic and Fetal Death, New York: Academic Press, 1980.

25. Special tabulations of data from the 2010 Colombian Encuesta Nacional de Demografía y Salud.

26. Singh S et al., Abortion Worldwide: A Decade of Uneven Progress, New York: Guttmacher Institute, 2009

27. Bradley SEK, Schwandt HM and Khan S, Levels, trends, and reasons for contraceptive discontinuation, DHS Analytical Studies, Calverton, MD, USA: ICF Macro, 2009, No. 20.

28. Faúndes A et al., Misoprostol for the termination of pregnancy up to 12 completed weeks of pregnancy, International Journal of Gynaecology and Obstetrics, 2007, 99(Suppl. 2):S172-S177.

29. Lara D et al., Pharmacy provision of medical abortifacients in a Latin American city, Contraception, 2006, 74(5):394-399.

30. Zamberlin N and Raiher S, Revisión del Conocimiento Disponible Sobre Experiencia de las Mujeres con el Uso del Misoprostol en América Latina, Lima, Peru: Consorcio Latinoamericano Contra el Aborto Inseguro; and Buenos Aires, Argentina: Centro de Estudios de Estado y Sociedad, 2010.

31. Prada E, Singh S and Villarreal C, Health consequences of unsafe abortion in Colombia, 1989-2008, paper presented at the International Union for the Scientific Study of Population Seminar on the Health, Social and Economic Consequences of Unsafe Abortion, San Juan del Rio, Mexico, Nov. 10-12, 2010

32. López-Escobar G and Riaño-Gamboa G, El aborto hospitalario en Colombia: estudio de un nuevo grupo de 3,901 casos en hospitales generales no universitarios, Investigaciones Cooperativas, Bogotá, Colombia: Programa Regional de Investigaciones en Fecundidad, 1981, No. 16

33. Profamilia, Salud Sexual y Reproductiva en Zonas Marginadas: Situación de las Mujeres Desplazadas, 2005, Bogotá, Colombia: Profamilia, 2006

34. Prada E et al., Unintended Pregnancy and Induced Abortion: Causes and Consequences, New York: Guttmacher Institute, 2011.

35. Barrera S, Progyne, Medellín, Colombia, personal communication, Feb. 2, 2010

\section{RESUMEN}

Contexto: Si bien en 2006 la Corte Constitucional de Colombia despenalizó el aborto inducido bajo circunstancias selectas, ningún estudio en el país ha examinado si la incidencia del procedimiento ha cambiado con respecto a la única estimación nacional previa, la del 1989.
Métodos: Los datos sobre el número de mujeres tratadas por complicaciones de aborto se obtuvieron con base en una encuesta representativa a nivel nacional aplicada en 300 instituciones públicas y privadas de salud. Las estimaciones sobre la probabilidad de que las mujeres que tienen un aborto sufran complicaciones y reciban tratamiento en una institución, se obtuvieron de una encuesta aplicada a 102 profesionales con amplios conocimientos sobre el tema. Se utilizaron técnicas de estimación indirecta para calcular medidas nacionales y regionales de aborto para 2008, mismas que se compararon con estimaciones para 1989. También se calcularon tasas de embarazos no planeados y distribuciones porcentuales de embarazos según su planeación y resolución.

Resultados: Se estima que en 2008, unas 93,300 mujeres recibieron tratamiento por complicaciones derivadas de abortos inducidos en instituciones públicas y privadas de salud. En ese año, se realizaron unos 400,400 abortos estimados, lo que se traduce en una tasa de 39 por 1,000 mujeres de 15-44 años, un ligero aumento con respecto a 1989 (36 por 1,000). Las tasas variaron ampliamente entre regiones, de 18 abortos por 1,000 mujeres en la región Oriental a 66 por 1,000 en Bogotá. Pese a la decisión de la Corte, se realizaron en 2008 solamente 322 abortos legales (Interrupciones Voluntarias del Embarazo, o IVE). Entre 1989 y 2008, la proporción de embarazos que terminó en abortos inducidos aumentó del 22\% al 29\%; y la proporción de embarazos que fueron no planeados aumentó del $52 \%$ al $67 \%$.

Conclusión: Es necesario mejorar la prestación y el acceso a los servicios anticonceptivos y de IVE, con el fin de responder a la creciente demanda que tienen las mujeres y parejas para la prevención del embarazo no planeado y para la prevención del aborto inseguro.

\section{RÉSUMÉ}

Contexte: Bien que l'avortement ait été légalisé dans certaines circonstances en Colombie en 2006, aucune étude nationale n'a cherché à déterminer si l'incidence de la procédure a changé depuis sa dernière estimation en 1989.

Méthodes: Les données relatives au nombre de femmes traitées pour complications après avortement proviennent d'une enquête nationalement représentative menée dans 300 établissements de santé publics et privés. Les estimations concernant la probabilité de complications et traitement en établissement des femmes ayant subi un avortement sont issues d'une enquête menée auprès de 102 professionnels informés sur la question. Les techniques d'estimation indirectes ont servi à calculer les mesures d'avortement nationales et régionales pour 2008, par rapport aux estimations publiées de 1989. Les nombres et les taux de grossesse non planifiée ont également été calculés.

Résultats: En 2008, le nombre de femmes traitées dans les établissements de santé publics et privés pour cause de complications d'IVG est estimé à 93.300. Le nombre d'IVG pratiquées est estimé à 400.400, soit un taux de 39 pour 1.000 femmes âgées de 15 à 44 ans, en légère hausse par rapport à 1989 (36 pour 1.000). Les taux varient largement suivant les régions, de 66 (Bogota) à 18 (Oriental). Malgré la nouvelle loi sur l'avor- 
tement, 322 IVG légales seulement ont été pratiquées en 2008. Entre 1989 et 2008, la proportion des grossesses interrompues volontairement est passée de $22 \%$ à 29\%, tandis que celle des grossesses non planifiées passait de $52 \%$ à $67 \%$.

Conclusion: Une amélioration des prestations et de l'accès à la contraception et à l'avortement légal est nécessaire si l'on veut répondre à la demande accrue, parmi les femmes et les couples, de prévention des grossesses non planifiées et de l'avortement non médicalisé.

\section{Acknowledgments}

This research was supported by the Dutch Ministry of Foreign Affairs. The authors are grateful to Fernanda Abella, Akinrinola Bankole, Lisa Remez, Gustavo Suarez and Cristina Villarreal for their input at various stages of the study. The authors also thank the eight members of the fieldwork team, for their invaluable contribution to carrying out the surveys; the 16 members of the project advisory committee in Colombia, who provided input on the study design and feedback on preliminary findings; and Suzette Audam, for her contributions to data management and processing. The views expressed herein are those of the authors and do not necessarily reflect the views of the United Nations.

Author contact: eprada@guttmacher.org 